\title{
ESCOLA RURAL, TEMPO ESCOLAR E CRIANÇAS TRABALHADORAS EM MINAS GERAIS (1892-1899)
}

\author{
Gilvanice Barbosa da Silva Musial* \\ lattes.cnpq.br/3290799012387538
}

\begin{abstract}
Resumo: Esse artigo apresenta parte dos resultados de uma pesquisa maior e tem como objetivos analisar as representações sobre escola rural, tempo escolar e crianças trabalhadoras em Minas Gerais na última década do século XIX. Buscamos apreender a existência de especificidades da escola rural quanto ao tempo escolar e seu público, crianças trabalhadoras. Como referencial teórico, trabalhamos com a noção de representações em consonância com o pensamento de Roger Chartier (2009). Ainda no âmbito deste trabalho, as noções de escolarização, cultura escolar e forma escolar são mobilizadas a partir de Faria Filho (2003), Frago (1995), Julia (2001) e Vincent; Lahire; Daniel (2001). Para escrita desse artigo trabalhamos com as seguintes fontes: legislação e relatórios de inspetores escolares (ambulante e extraordinário). Podemos afirmar que havia uma especificidade na forma de organização de várias escolas rurais. Ela estava diretamente relacionada com a territorialidade na qual a escola rural estava inserida e também com as condições socioculturais e econômicas de suas populações. Diferentemente das representações produzidas pelo inspetor Extraordinário sobre a escola rural, o tempo escolar e as crianças e suas famílias, a análise das informações contidas nos relatórios indicam-nos uma preocupação dos pais em enviarem seus filhos para a escola apesar da pobreza, da distância, da fome, da seca e da importância do trabalho dessas crianças na manutenção das suas famílias.
\end{abstract}

Palavras-chave: Instrução primária; História da escola rural; Tempo escolar; Crianças trabalhadoras.

\section{RURAL SCHOOL, SCHOOL TIME AND CHILDREN LABORERS IN MINAS GERAIS (1892-1899)}

\begin{abstract}
This article presents part of the results of a larger research and intends amongst its objectives to analyze the representations about rural school, school time and children laborers in Minas Gerais in the last decade of the 19th century. We aim at understanding the existence of specificities of the rural school in terms of school time and its public, the children laborers. As for our theoretical framework, we employ the

\footnotetext{
* Doutora em Educação. Docente da Universidade Federal da Bahia (Brasil). Contato: gilvanicemusial@yahoo.com.br.
} 
concept of representations following the line of thinking of Roger Chartier (2009a). Within the scope of this work, the concepts of schooling, school culture and school format are mobilized departing from Faria Filho (2003), Frago (1995), Julia (2001) and Vincent; Lahire; Daniel (2001). This article is based on the following sources: Legislation and School Inspectors' Reports (itinerary and extraordinary). We can affirm that there has been a specificity in terms of the organization of several rural schools. It was directly related to the territory on which the rural school was located and also to the sociocultural and economic conditions of its populations. Differently from the representations produced by the extraordinary inspector about the rural school, school time and children and their families, the analysis of the information contained in the reports indicates a concern of the parents in sending their children to school despite poverty, distance, hunger, drought and the important of these children's labor in their families' income.

Keywords: Primary education; History of the rural school; School time; Children laborers.

\section{Introdução}

Esse capítulo apresenta parte dos resultados de uma pesquisa maior e tem como objetivos refletir sobre as representações sobre escola rural, tempo escolar e crianças trabalhadoras em Minas Gerais na última década do século XIX. Como referencial teórico, trabalhamos com a noção de representações em consonância com o pensamento de Roger Chartier (2009, p. 210). Segundo o autor, essa noção tem sido um suporte precioso para que sejam percebidas e articuladas "as diversas relações que os indivíduos e os grupos estabelecem com o mundo social". ${ }^{1}$ Para Chartier, a noção de representações nos conduz a um duplo sentido. Conforme uma de suas acepções, ela pode "fazer presente uma ausência, mas também exibir

\footnotetext{
${ }^{1}$ Chartier (2009), ao tomar a obra de Marin (1985), como ponto de partida para a análise da teoria da representação, ressalta que essa obra possibilitou aos historiadores transformações na compreensão sobre o mundo social.
} 
sua própria presença através de uma imagem, assim como transformar aquilo que olhamos no objeto olhado" (CHARTIER, 2009, p. 205). ${ }^{2}$

Ainda no âmbito deste trabalho, as noções de escolarização e de cultura escolar são mobilizadas. A palavra escolarização pode ser compreendida em um duplo sentido, conforme Luciano M. de Faria Filho (2003, p. 78). O primeiro sentido refere-se à instauração de processos e políticas relativas à organização de uma ou mais redes de instituições, mais ou menos formais, responsáveis, seja pelo ensino elementar da leitura, da escrita, do cálculo, seja, no mais das vezes, pelo ensino da moral e da religião. O segundo sentido relaciona-se ao processo de produção paulatina de referenciais sociais, tendo a escola, ou a forma escolar de socialização e transmissão de conhecimento, como eixo articulador de seus sentidos e significados. Essa última acepção remete àquela denominada de forma escolar, definida por Guy Vincent; Bernard Lahire; Daniel Thin (2001). De acordo com essa acepção, a configuração e a difusão da escola no mundo moderno também se realizam pela sua crescente influência para fora dos seus muros.

Quanto à noção de cultura escolar, considerada fundamental para as análises deste capítulo, é possível afirmar que tal noção nos permite compreender elementos-chave, os quais compõem o fenômeno educativo, tais como: os tempos, os espaços, os sujeitos, os conhecimentos e as práticas relacionados à escola. Assim, a cultura escolar pode ser entendida como

a forma como, em uma situação histórica concreta e particular, são articulados e representados, pelos sujeitos escolares, as dimensões espaço-temporais do fenômeno educativo escolar, os conhecimentos, as sensibilidades e os valores a serem transmitidos, a materialidade e os métodos escolares (FARIA FILHO, 2003, p. 85).

\footnotetext{
2 No texto em francês : "rendre présente une absence, mais aussi exhiber sa propre présence en tant qu'image et, ainsi, constituer celui qui la regarde comme sujet regardant $»$.
} 
Essa noção foi esboçada a partir das contribuições de Viñao Frago (1995) e de Dominique Julia (2001). Ao operar com esse conceito, pretendemos apreender a cultura escolar por meio da análise dos tempos e dos sujeitos da escola. Buscamos, pois, apreender a existência de especificidades da escola rural quanto ao tempo escolar e seu público, crianças trabalhadoras.

Para escrita desse capítulo trabalhamos com as seguintes fontes: legislação, relatórios de inspetores escolares (ambulante e extraordinário), relatórios do Secretário de Estado dos Negócios do Interior e mapas de escolas.

\section{A escola rural e o tempo escolar}

Pensar sobre o tempo escolar implica considerar, em primeiro lugar, o tempo como construção social e humana, múltipla e plural (LUHMANN, s/d, p. 161-182 apud VIÑAO FRAGO, 1995, p. 72). É também preciso considerar que essa construção assume feições variadas em diferentes grupos e espaços sociais. Ela diz respeito a uma variedade de relações entre o antes, o agora e o depois - o passado, o presente e o futuro.

Tomando, assim, o tempo como uma construção social, trabalhamos com a noção de tempo escolar enquanto uma das modalidades temporais. Dessa forma, o tempo escolar apresenta-se como um tempo diverso e plural, individual e institucional, condicionante e condicionado por outros tempos sociais (VIÑAO FRAGO, 1995, p. 72). Segundo o autor, do ponto de vista institucional, pelo menos formalmente, o tempo escolar pode ser considerado como prescrito e uniforme. Porém, do ponto de vista individual, ele é múltiplo e pode adquirir diferentes feições, o que nos levaria a considerá-lo sempre no plural, como tempos escolares.

O tempo escolar institucional pode apresentar diferentes configurações e níveis, os quais podem se organizar de diferentes formas, segundo a duração de um determinado curso, o ciclo, anos de estudos, um semes- 
tre, um mês de atividades, as horas em que diferentes atividades são organizadas no interior de um dia de trabalho; pelo tempo de que dispõe o professor para trabalhar determinados conteúdos ou para preparar seu trabalho; conforme o calendário escolar. Mas como o tempo estava organizado nas escolas rurais de instrução primária sob responsabilidade do governo do estado de Minas Gerais no final do século XIX? Havia distinções entre o tempo escolar institucional e aquele vivenciado nas escolas rurais?

De acordo com o art. 83, capítulo II, da Lei no 41, de 1892, "as escolas ruraes, districtaes e urbanas funcionarão em duas secções: das $8^{1 / 2}$ ás 11 da manhã e de 1 hora ás $3^{1 / 2}$ da tarde”. Embora a lei estabeleça a distinção entre as escolas de instrução primária, do ponto de vista dos seus currículos, dos salários dos seus professores, da frequência legal mínima, do ponto de vista do tempo escolar, a referida lei não estabelece distinção. Nesse sentido, em relação ao tempo escolar, os espaços sociais rurais não se apresentavam como uma realidade distinta da escola distrital ou da escola urbana. A racionalidade do tempo escolar adquiriu uma autonomia perante a territorialidade rural e esperava-se que os sujeitos do campo se adaptassem à temporalidade da escola.

É fato que esse não é um tempo parcelado e controlado, como o que se verá com a criação dos grupos escolares, no início do século XX. No cotidiano da classe, o professor possuía, ainda, liberdade para a organização de seu trabalho no interior de uma quantidade de horas determinadas pelo regulamento. Mesmo que a organização do tempo escolar ainda não tivesse atingido um grau de detalhamento, tal como veremos algum tempo depois, detalhamento esse que seria considerado pelos teóricos da forma escolar um dos elementos fundamentais de sua constituição, é possível perceber, nos relatórios do Inspetor Extraordinário Domiciano Rodrigues Vieira, a verificação do cumprimento, por parte dos professores das escolas rurais, do horário "regimental".

A exigência de que professores e alunos respeitassem o regulamento aparece como um componente das relações de poder, tal como explicitada por Vincent; Lahire; Thin (2001), quando analisaram a emergência da forma escolar na sociedade francesa. Os autores afirmam que, a partir de 
um determinado momento3, "na escola não se obedece mais a uma pessoa, mas a regras suprapessoais que se impõem tanto aos alunos quanto aos mestres”. Passa a ser necessário obedecer-se ao regulamento.

Para determinadas comunidades, como as rurais, o espaço físico pode interferir, cotidianamente, nos tempos escolares. Não é raro encontrarmos relatos de inspetores que ressaltam as distâncias percorridas pelos alunos de suas casas até a escola. Nesses casos, muitas crianças precisavam caminhar quilômetros, que se transformavam em horas, para chegar à escola e, depois, para retornar para suas casas.

Os conflitos entre as diferentes temporalidades, a legal e a local, vividos pelos sujeitos dos espaços sociais rurais, aparecem nos relatórios do Inspetor Extraordinário Domiciano Rodrigues Vieira. Nas suas visitas, o referido inspetor verificava o horário de funcionamento das escolas, consultava o livro de ponto, conversava com pessoas da comunidade a fim de averiguar se o regulamento estava sendo cumprido. O conflito, entre a racionalidade do tempo escolar "regimental" e as condições de frequência dos alunos, apresentava-se, nos registros de Domiciano Vieira, quando ele ressaltava as longas distâncias percorridas pelos alunos para chegar à escola e para voltar às suas casas, após as aulas. Diante dessa realidade, as professoras criavam estratégias na organização do tempo escolar, que se tornava, então, diferente do tempo "regimental", a fim de atender à solicitação dos pais. Esse tempo escolar, produzido, portanto, pelos sujeitos mais diretamente envolvidos na dinâmica das aulas, era marcado, também, pela dinâmica do ambiente doméstico. Nas palavras do Inspetor Extraordinário,

Percebi que a professora recebe os discipulos a qualquer hora do dia, dá-lhes uma péssima licção, muito ligeira, e os despede. Desculpou-se da irregularidade com que dá assim as aulas dizendo que os alunnos moram muito longe (6, 7, 8 e 9 kilometros), não podendo comparecer e retirar-se a hora regimental.4 (p. 70).

\footnotetext{
3 Segundo Vincent et al. (1995, p.28), entre os séculos XVII e XIX, na França urbana, "é possível assistir à constituição de formas relativamente invariáveis (isto é, recorrentes) de relações sociais: certas formas escolares de relações sociais".

4 APM. Correspondências dos Inspetores Escolares da 1a a 4a Circumscripção, volume SI 3958, 1899. Fundo: Secretaria do Interior.
} 
Além do tempo da legislação e da inspeção, é preciso considerar o tempo dos professores, dos alunos e das comunidades onde determinada escola está inserida. O tempo regimental de início e de término das aulas, como também o próprio calendário escolar, sofriam diretamente a influência de fatores como a necessidade de mão-de-obra nos tempos de plantio e colheita. Essas épocas obrigavam as crianças a se ausentarem da escola para participar, com a família, dos trabalhos na lavoura.

Apesar de ser distinta, a escola rural cumpria, ou tinha de cumprir, o tempo regimentar. 5 As peculiaridades da vida das populações rurais não foram consideradas ao ser efetivada a reforma da instrução primária do estado de Minas Gerais, de 1892. Nesse sentido, os tempos destinados ao plantio e à colheita, atividades inerentes às populações rurais, parecem interferir nas condições de frequência das crianças, que, além disso, como já se destacou, tinham de percorrer longas distâncias para chegar à escola. Sobre esses aspectos, em relação ao que ocorria na cadeira rural de Engenho Secco, em Sabará, o Inspetor registrou:

Muito poucos meninos moram perto; quase todos caminham no mínimo 1 kilometro para ir até lá. Não sei para que se criou escola neste logar. Queixa-se o professor de que os alunnos não comparecem vivem occupados quase todo o anno nos trabalhos rústicos; não vão á escola na época do plantio de feijão; não vão á escola no tempo das capoeiras, não vão á escola durante a colheita do café (como agora)! Encontrei sete (7) alunnos sujos, imundos. ${ }^{6}$ (p. 69).

Além da inserção das crianças no mundo do trabalho, as condições materiais da escola também interferiam na organização do tempo escolar. Na cadeira mista rural noturna de Marzagão, Sabará, a professora afirmou que alterou o horário de funcionamento da aula com autorização do Inspetor Municipal, pois a falta de luz dificultava a aula noturna. Visto que os alunos eram trabalhadores da fábrica de tecidos, recebia-os por turmas

\footnotetext{
5 Esse tempo regimental era o mesmo para as escolas rurais, urbanas e distritais. ${ }^{6}$ APM. Correspondências dos Inspetores Escolares da 1a a 4a Circumscripção, volume SI 3958, 1899. Fundo: Secretaria do Interior.
} 
A professora disse-me que leciona das 10 horas do dia ás 4 da tarde, por ordem escripta que mostrou-me do ex. Inspetor municipal, Dr. Carlito dos Santos Pinto, que assim obviou a difficuldade em que a mestra diz ter-se achado por falta de luz para a aula nocturna queixando-se de não a fornecer o Governo. Os alunnos são recebidos, lecionados e despedidos por turmas, afim de que elles possam se ocupar nos trabalhos da fabrica de tecidos sem prejuízo dos estudos.7 (p. 23).

Embora noturna, a escola rural de Marzagão funcionava durante o dia. Nesse caso percebem-se claramente as possibilidades de alteração dos tempos escolares, que vão sendo negociados com os inspetores municipais, com patrões, pais e responsáveis pelas crianças. Nesse caso, a professora parece organizar os alunos em turmas e recebê-las em horários diferentes do dia.

Organizar a cadeira por turmas era também uma estratégia da professora da escola rural mista de Pinhões, em Santa Luzia. Essa re-organização do tempo escolar afetava o trabalho do Inspetor Extraordinário Domiciano Rodrigues Vieira que se ressentia do tempo gasto com idas e vindas, para visitar as escolas no horário regimental. O tempo gasto, percorrendo longas distâncias, incomodava-o. Porém, esse desconforto não sensibilizava seu olhar para as adaptações feitas por algumas professoras. De acordo com Domiciano Rodrigues Vieira,

Como esta escola está distante da cidade, onde primeiro almocei, só pude comparecer chegando a 1 hora e 35 minutos da tarde, encontrando os alumnos supra; pelo livro de ponto verifiquei que a professora despedira (como costumava, e má disse) a seguinte turma que mora longe, antes da hora regimental $\mathrm{p}^{\mathrm{a}}$. satisfazer $\mathrm{o}$ pedido dos Paes. ${ }^{8}$ (p. 39).

A naturalização e a autonomia de um tempo sempre regulado aparecem no discurso do Inspetor Extraordinário Domiciano Rodrigues Vieira, quando descreveu os caminhos percorridos para chegar até as escolas rurais:

7 APM. Correspondências dos Inspetores Escolares da 1a a 4a Circumscripção, volume SI 3958, 1899. Fundo: Secretaria do Interior.

8 APM. Correspondências dos Inspetores Escolares da 1a a 4a Circumscripção, volume SI 3958, 1899. Fundo: Secretaria do Interior. 
obrigado a fazer longas, demoradas visitas, chegando inesperadamente e tudo dentro do tempo que decorre das dez horas da manha as duas da tarde. Muitas vezes perderia o dia si me depusesse a esperar que se me fizesse um almoço (...) viajei então por almoçar em taes dias, só para ser expedito e dar conta no mais breve tempo possível desta ingrata tarefa (p. 3).9

O tempo escolar regimental contrasta com o tempo vivido pelas comunidades rurais e mesmo com o tempo das comunidades urbanas, no final do século XIX, em Minas Gerais. Faria Filho (2000), quando estudou a criação dos grupos escolares em Belo Horizonte, no início do século XX, ressaltou que uma das estratégias para impor uma determinada representação de cultura escolar foi a construção dos grupos escolares, cuja organização do tempo escolar baseava-se em momentos parcelados rígidos para as atividades cotidianas. Segundo o autor, "num meio onde a escola até então era uma instituição que se adaptava à vida das pessoas - daí as escolas isoladas insistirem em ter seus espaços e horários próprios, organizados de acordo com a conveniência da professora, dos alunos e levando em conta os costumes locais" -, não bastava ao estado interferir na organização espacial das escolas; foi necessário criar novas referências de tempo e legitimá-las (p. 69).

Mas, essa era uma especificidade da escola rural ou nela as contradições se apresentavam com maior ênfase? As contradições entre o tempo escolar definido no regulamento da instrução pública através do decreto $\mathrm{n}^{\mathrm{0}} 655$, de 1893, e a prática dos professores, de uma maneira geral, aparecem no relatório do Secretário de Estado dos Negócios do Interior, Dr. Henrique Augusto de Oliveira Diniz, de 1897, da seguinte forma:

Não obstante a experiência de três annos haver demonstrado a impraticabilidade e a inconveniência mesmo da disposição do art. 51 do citado regulamento ${ }^{10}$ que manda que as escolas publicas sejam divididas em duas turmas, funccionando em horas differentes ainda não foi revogada aquella disposição legal. Persistindo ella, tenho continuado, como me cumpre, a reiterar minhas

9 APM. Correspondências dos Inspetores Escolares da 1a a 4a Circumscripção, volume SI 3958,1899 . Fundo: Secretaria do Interior.

${ }^{10}$ Regulamento $\mathrm{n}^{\circ} .655$, de 1893. 
recommendações aos inspectores escolares no sentido de ser fielmente observado o preceito regulamentar, ponderando-lhes que ao poder executivo fallece competência para modifical-o.

Com effeito, este é incontestavelmente preferível e quanto maior for a demora em restabelecel-o, mais prejudicadas serão as crianças e também sacrificados os interesses do ensino, que jamais poderá ser ministrado com efficacia e proveito, mantida a divisão das aulas em duas turmas. Reportando-me ao que já expendi anteriormente, seja-me licito solicitar de novo as providencias que no caso a experiência aconselha (p. 27). ${ }^{11}$

Percebe-se, nesse discurso do Secretário, por um lado, a "impraticabilidade" de uma determinação regimental que propõe a organização do tempo escolar em duas turmas, como informado anteriormente. Por outro lado, o Secretário informa-nos que o referido horário não estava sendo seguido, que não havia aumentado o número de escolas que o seguiam do ano anterior para o ano de 1897 e que as "justas reclamações de professores, autoridades literárias e pais de alunos"12 contra a disposição legal, essas, sim, haviam aumentado. De acordo com o Secretário, eles solicitavam retorno ao horário anterior (relatório do Secretário de Estado dos Negócios do Interior, Dr. Henrique Augusto de Oliveira Diniz, de 1897, p. 27).

\section{A escola rural, as crianças trabalhadoras e suas famílias}

Uma vez que conhecemos um pouco mais sobre as representações sobre o tempo escolar relativo às escolas rurais, outras questões se apresentam a nós. Nesse sentido, perguntamo-nos: Quem eram os alunos dessas escolas? Quais representações foram construídas sobre esses sujeitos? Os inspetores escolares nos dão alguns indícios sobre quem eram as crianças que frequentavam as escolas rurais da região estudada.

${ }_{11}$ Relatório apresentado ao Presidente do estado de Minas Gerais pelo Secretario dos Negócios do Interior, Henrique Augusto de Oliveira Diniz em 1897, volume I e II. Disponível em: <http://www.crl.edu/brazil/provincial/minas_gerais $>$. 12 Ibidem. 
Nos diferentes documentos acessados, procuramos apreender quem eram as crianças que frequentavam as escolas rurais em Minas Gerais, no final do século XIX. Pelos diferentes relatos, elas seriam majoritariamente pobres, negras e mestiças, de idades variadas (de 6 a 17 anos). Os alunos percorriam longas distâncias para ir à escola e pareciam fazer isso na companhia de outras crianças; possivelmente, irmãos e primos seus. Eles ocupavam seu tempo com trabalhos na lavoura - plantio e colheita -, na fábrica, nos afazeres domésticos e frequentam a escola de instrução primária portando, na maioria das vezes, seus próprios materiais - lousas ou livros.

Ao visitar a escola rural mista da Fábrica São Vicente, Domiciano Rodrigues Vieira indicou que a professora era uma péssima normalista. Na sua escola, teriam permanecido somente alunos pobres. Segundo o Inspetor, o médico e diretor da Fábrica, como também alguns de seus funcionários, contrataram outras professoras para ensinar a seus filhos, após conhecerem o trabalho da mestra. Ao analisar esses dados, recolhidos das fontes da pesquisa sobre a escola rural em Minas Gerais no final do século XIX, o que nos chama a atenção nesse discurso é o fato de a escola de instrução primária ter sido um local de instrução predominantemente de crianças pobres. Nesse caso específico, o Inspetor Extraordinário justificou a presença exclusiva de crianças pobres na escola pública pelo fato de seus pais não conseguirem pagar uma professora particular.

Quando visitou a escola rural do sexo masculino de Córrego Grande, em Sabará, Domiciano Rodrigues Vieira fez o seguinte comentário a respeito dos alunos da instituição: "os meninos que vi são quase todos negrinhos; poucos pardos e muito poucos brancos" (p. 112). ${ }^{13}$ Essa escola pareceu ser marcada não só pela presença de professoras negras ${ }^{14}$, como também pela presença de crianças negras e mestiças. Mais uma vez, o discurso do Inspetor traz, em sua composição, elementos das teorias racistas. As crianças não eram negras, eram "negrinhas". Os demais eram pardos e brancos. E em relação à pobreza dos alunos? Como ela foi retratada nos relatórios dos inspetores escolares?

13 APM. Correspondências dos Inspetores Escolares da 1a a 4a Circumscripção, volume SI 3958, 1899. Fundo: Secretaria do Interior.

14 Para ver mais sobre essa questão: MUSIAL, 2011. 
Em relatório de setembro de 1894, o Inspetor Manoel Antonio Pacheco Lessa escreveu: "repito hoje o que nos outros meos relatórios já tenho vos dito, em todas as escolas percorridas há falta de tudo e especialmente de livros para serem distribuídos á alumnos pobres" (p. 1). ${ }^{15} \mathrm{Em}$ setembro de 1897, ao visitar as escolas de Sabará, o Inspetor afirmou que as escolas do município achavam-se servidas de bons professores que prestariam os melhores serviços se tivessem boa inspeção, cômodos apropriados e livros necessários para seus alunos, "na maior parte indigentes e necessitados até da roupa indispensável para apresentarem-se com decência na escola" (p.2). ${ }^{16}$ Considerando os relatórios de 1894 e 1897, parecenos ter havido uma alteração no discurso do inspetor quando analisamos esses dois textos. No primeiro, foi ressaltada a necessidade de material para os alunos pobres; no segundo, os alunos eram quase todos indigentes. Nesse momento, parece ter ocorrido um deslocamento das condições dos alunos das escolas de instrução primária visitadas pelo Inspetor: de pobres eles teriam passado para a condição de indigentes. Mas será que, de fato, as condições econômicas se agravaram a ponto de provocar essa alteração?

Um dos aspectos que mais chamou a atenção do Inspetor Extraordinário refere-se aos argumentos dos pais sobre a impossibilidade de manter as crianças na escola. Quando visitou a escola rural mista de Castanheira, em Santa Luzia, Domiciano Rodrigues Vieira afirmou que seria difícil ter frequência na escola porque "a população é muito pobre e queixa-se de que não tem quase o que comer". Segundo o Inspetor, "dizem que com muito sacrifício enviam as creanças á mestra, pois por vezes não tem as famílias pobres almoço ate a hora escolar e muitos comem uma vez ao dia” (p. 50).17

Em contrapartida, quando visitou a escola rural de Corações, em Sabará, Domiciano Rodrigues Vieira teria observado uma situação um pouco diferente daquela encontrada em Santa Luzia. Conforme o Inspetor,

\footnotetext{
15 APM. Correspondência recebida pelo Secretário do Interior sobre a inspeção de ensino, volume SI 663, 1894.

16 APM. Correspondência recebida pelo Secretário do Interior sobre a inspeção de ensino, volume SI 692, 1897.

${ }_{17}$ APM. Correspondências dos Inspetores Escolares da 1a a 4a Circumscripção, volume SI 3958, 1899. Fundo: Secretaria do Interior.
} 
Alguns alumnos moram perto da escola, outros moram longe e vi que alguns que moram longe são assíduos, mesmo com sacrifícios. Tudo depende das famílias; quando há boa vontade e interesse em aprender não há difficuldade para se ir a escola (p. 93).18

Entretanto, na introdução do seu relatório sobre o município de Santa Luzia do Rio das Velhas, Domiciano Rodrigues Vieira apresentou seu parecer sobre as escolas rurais da seguinte maneira:

Taes escolas nunca aproveitarão, não só porque os seus professores na maioria são pouco preparados, como porque ahi jazem sem fiscalização alguma entre o povo rústico, indifferente á educação das crianças e que longe de auxiliar este grande intuito, muitas vezes chega a suppôr ser um favor envial-as ao mestre, queixando-se grande numero de tabareos de se aggravar com isso a sorte precária de sua pobreza (ó cúmulo da animalidade humana!), censurando outros ao Governo por não fornecer além de livros até vestimentas! Cancei-me de ouvir dizer que não têm o que comer, que precisam dos filhos para trabalhar que é um sacrifício enorme fazel-o caminhar um dois e três kilometros para ir a escola, certos dias, sem almoço! Entretanto, cada aldeia de três, quatro casas, quer ter sua escola mantida pelo Estado em troca do seu voto eleitoral a um deputado ou senador (p. 3-4). [Grifo no original]. ${ }^{19}$

Parece-nos que, nesse momento, as forças políticas locais tinham certo poder de negociação. Talvez pela presença da política municipalista e pela relativa autonomia dos distritos, as comunidades rurais estivessem mais próximas das esferas de decisão. Outro aspecto que chama a atenção é o fato de essas comunidades demandarem escola para suas crianças e insistirem na existência de crianças suficientes para garantir a frequência legal. O registro do Inspetor Extraordinário explicita, já nesse momento, um dos grandes desafios colocados à educação das populações rurais no Brasil, qual seja, conciliar os processos de escolarização, no duplo sentido

${ }_{18}$ APM. Correspondências dos Inspetores Escolares da 1a a 4a Circumscripção, volume SI 3958, 1899. Fundo: Secretaria do Interior.

19 Ibidem. 
apresentado por Faria Filho (2003) à territorialidade dos espaços sociais rurais ${ }^{20}$.

Quando visitou a escola rural mista de Castanheiras, em Santa Luzia, Domiciano Rodrigues Vieira afirmou ainda que a professora foi avisada por seu cunhado sobre a presença do Inspetor na região e que, "sendo estimada dos tabaréus, ficou de atalaia com os alumnos", à espera da sua visita até seu aparecimento. De acordo com Domiciano, "os aldeiões, receiosos de ficarem sem a escola e a professora aterrada com elles se empenhou, de modo que assim, como V.Ex ${ }^{\text {cia }}$. vai ver, encontrei relativamente a população da aldeia, grande número de creanças, sendo poucos os que deixaram de comparecer" (p. 50-51).21 Eram várias as estratégias utilizadas pelas comunidades rurais para garantir, lá, a permanência das escolas. Em diferentes momentos, alguns inspetores municipais e mesmo moradores das comunidades rurais, afirmam existir grande número de crianças internadas pelas 'capoeiras'.

Os espaços sociais rurais pareciam não ser, na visão do Inspetor Extraordinário, locais ideais para a instalação de escolas de instrução primária. Sua população, na perspectiva de Domiciano Rodrigues Vieira, não valorizava a escola, as crianças não a frequentavam, estavam entregues aos trabalhos rústicos, as autoridades não à fiscalizavam, os espaços físicos das instituições eram precários, as casas eram muito distantes das escolas. No olhar do Inspetor, parecia mesmo não haver alternativa de civilização para as populações dos espaços rurais.

De acordo com os relatórios do Inspetor Extraordinário Domiciano Rodrigues Vieira, na “cadeira rural mixta de Campanha”, em Sabará, “existem matriculados 51; frequentes, de 33 a 46, conforme livro de ponto, na

\footnotetext{
20 Para Faria Filho (2003), o primeiro sentido refere-se à instauração de processos e políticas relativas à ‘organização' de uma ou mais redes de instituições, mais ou menos formais, responsáveis, seja pelo ensino elementar da leitura, da escrita, do cálculo, seja, no mais das vezes, pelo ensino da moral e da religião. O Segundo sentido relaciona-se ao processo de produção paulatina de referenciais sociais, tendo a escola, ou a forma escolar de socialização e transmissão de conhecimento, como eixo articulador de seus sentidos e significados.

${ }^{21}$ APM. Correspondências dos Inspetores Escolares da 1a a 4a Circumscripção, volume SI 3958, 1899. Fundo: Secretaria do Interior.
} 
média 40, diariamente, estiveram presentes á visita 33”. No município de Santa Luzia, na "cadeira rural mixta de Padre Miguel", existiam "matriculados 54; frequentes diariamente de 30 a 40; estiveram presentes á visita os 38 supra mencionados". Na escola rural do sexo masculino de Bexigas, estavam "matriculados 66 alumnos; a frequência diária e de 30 a 40 e o resumo da frequência trimestral de 15 a 25". Na cadeira rural, do sexo masculino de Lapinha "existiam matriculados 57 alumnos e a frequencia segundo a folha do ponto é no mínimo 20". Finalmente, na "cadeira rural mixta de Cypriano", estavam "matriculados 46; frequentes no mínimo 19 e no maximo 35 ".22

Dos três municípios visitados, Villa Nova de Lima é o que apresentava menor número de escolas de instrução primária como um todo e, também, de escolas rurais. Trata-se também do município com maior problema de frequência nas escolas rurais. Das sete escolas rurais existentes, duas estavam vagas, e cinco, providas. Três apresentaram frequência inferior à estabelecida pela legislação, ou seja, 15 alunos frequentes.

Do município de Sabará, das dez escolas rurais providas, apenas uma não apresentou frequência legal. Ao final do relatório, Domiciano Rodrigues Vieira (1899) afirmou: "ahi tendes, Exmo. Sr. Dr. Secretario do Interior, dia a dia o meu trabalho de um mês com esta horivel commissão. (...) Percorri, ao sol ardente, as sinuosidades do município de Sabará em busca destas escolas, que não valem nem o sacrifício que fiz” (p. 124).

Por fim, Santa Luzia, o município com maior número de escolas de instrução primária, tinha 40 instituições, também apresentava o maior número de escolas rurais providas: dezessete (17). Desse total, somente três escolas apresentaram frequência irregular.

${ }^{22}$ Arquivo Público Mineiro (APM). Correspondências dos Inspetores Escolares da 1a a 4a Circumscripção, volume SI 3958, 1899. Fundo: Secretaria do Interior. 


\section{Considerações finais}

Em relação a regulação do tempo escolar é possível pensar que, em alguma medida, era negociada com professores, pais e comunidades. $\mathrm{O}$ que percebemos é que a organização do tempo escolar em dois turnos, estabelecido pela lei $\mathrm{n}^{0}$ 41, de 1892, e questionado pelo Secretário dos Negócios do Interior, não era o mesmo exigido pelo Inspetor Extraordinário em 1899. Essa diferença nos indica uma alteração nesse aspecto da referida lei. Em relação ao tempo escolar, foram necessários o início do século XX e a criação dos grupos escolares, para que a adoção de dois turnos na escola primária fosse uma realidade, tal como explicita Faria Filho (2000). Conforme Vincent; Lahire; Thin (2001), a emergência da forma escolar, que implicou a delimitação de espaços e tempos determinados, não aconteceu "sem dificuldades, conflitos e lutas, de tal sorte que a história da escola está repleta de polêmicas e posições exacerbadas, por sua vez, sempre 'em crise"” (p. 10).

Nessa direção, podemos afirmar que havia uma especificidade na forma de organização de várias escolas rurais visitadas pelo Inspetor Extraordinário. Ela estava diretamente relacionada com a territorialidade na qual a escola rural estava inserida e também com as condições socioculturais de suas populações, nas quais o trabalho da família na lavoura e na colheita era fundamental para a garantia da subsistência do grupo familiar e as crianças estavam envolvidas nessas tarefas. Mas é preciso salientar que vários estudos sobre educação nesse período indicam que também na cidade o trabalho das crianças, muito importante na manutenção dos grupos familiares pobres, era fundamental e impunha à escola certa flexibilidade nos horários.

Ao analisarmos as informações sobre a frequência nas escolas visitadas por Domiciano Rodrigues Vieira, os dados contrastam com a fisionomia do rural esboçado pelo Inspetor Extraordinário. Em alguns locais, Domiciano Rodrigues Vieira admirava-se com a frequência e dizia não acreditar no que observava; em outros lugares, suspeitava da forma como os professores registravam a presença dos alunos. Havia também localidades 
onde ele culpava os pais de não enviarem seus filhos à escola, de se queixarem da pobreza. Entretanto, os dados presentes nos seus relatórios indicam-nos a existência de um espaço rural povoado, evidentemente, de forma diferente do urbano, mas povoado. Diferentemente do que o Inspetor representava a escola rural, o tempo escolar e as crianças, as informações de seus próprios relatórios indicam-nos ainda uma preocupação dos pais em enviarem, sim, seus filhos para a escola apesar da pobreza, da distância, da fome, da seca e da importância do trabalho dessas crianças na manutenção das suas famílias.

Ao tentarmos apreender a existência de uma específica escola rural em Minas Gerais no final do século XIX, a partir da análise das representações sobre o tempo escolar e sobre as crianças que frequentavam as escolas rurais, nos foi possível, como ressaltado por Faria Filho (2003), compreender como em uma situação histórica concreta e particular, foram articulados e representados, pelos sujeitos escolares, as dimensões espaçotemporais do fenômeno educativo escolar, em especial da escola rural, os conhecimentos, as sensibilidades e os valores a serem transmitidos.

\section{Referências}

CHARTIER, R. Au bord de la falaise: l'histoire entre certitudes et inquiétudes. Paris: Ed. Albin Michel, 2009.

FARIA FILHO, L. M. Dos pardieiros aos palácios: cultura escolar e urbana em Belo Horizonte na Primeira República. Passo Fundo: UPF, 2000.

. O processo de escolarização em Minas Gerais: questões teóricometodológicas e perspectivas de análise. In: FONSECA, T. N. L.; VEIGA, C. G. (org.). História e historiografia da Educação no Brasil. Belo Horizonte: Autêntica, 2003, p.77-97.

JULIA, D. Cultura escolar como objeto histórico. Revista Brasileira de História da Educação, São Paulo, n. 1, p. 63-82, 2001. 
LUHMANN, N. El futuro no puede empezar: estructuras temporales en la sociedad moderna. In. TORRES, R. R. Tiempo y Sociedad. Madrid: Centro de Invesigacines Sociológicas, (s/d).

MUSIAL, G. B. S. A emergência da escola rural em Minas Gerais: quando a distinção possibilita a exclusão (1892-1899). Tese (Doutorado) - Universidade Federal de Minas Gerais, Belo Horizonte, 2011.

VIÑAO FRAGO, A. Historia de la educación e historia cultural: posibilidades, problemas, cuestiones. Revista Brasileira de Educação, Campinas, n. o, p. 63-82, 1995.

VINCENT, G.; LAHIRE, B.; THIN, D. Sobre a história e a teoria da forma escolar. Educação em Revista, Belo Horizonte, n.33, p.7-48, jun. 2001.

Recebido em 05 de maio de 2017. Aprovado em 02 de junho de 2017. 